\title{
A tradição do ator entre Oriente e Ocidente
}

\author{
Ricardo Gomes
}

ransitar entre diferentes culturas requer um extremo cuidado na avaliação de cada conceito em cada situação específica. Seeger, no seu texto "Music and dance" demonstra como para os índios Suiá o que nós entendemos como "música" (sons organizados) e "dança" (movimentos corporais organizados dentro de um ritmo) fazem parte de uma mesma realidade e não podem ser separados um do outro, pois estão sempre associados e são designados por uma única palavra. A partir desta observação ele se pergunta:

Podemos designar uma performance como "música" quando não existe este conceito na comunidade? Podemos, desde que seja claro para nós que os termos "música" e "dança" são nossos próprios meios para generalizar tipos de ações humanas que não têm o mesmo significado para grupos diferentes de pessoas. (...) Mais importante que chegar a uma definição universal é reconhecer que todas as sociedades humanas têm várias formas de linguagem, vários estilos de movimentos e várias maneiras de criar e estruturar sons não-vocais. Os caminhos específicos que cada uma percorre para dividir linguagem, movimento e produção sonora em unidades significati- vas varia enormemente de um lugar para o outro (Seeger, 1997, p. 545).

Para tentar compreender uma cultura diversa não podemos usar nossos próprios parâmetros, mas ao mesmo tempo só é possível olhar o outro a partir do próprio ponto de vista. Quem se propõe a um estudo intercultural "deve constantemente trabalhar no caminho de ida e volta entre a linguagem e os conceitos de sua própria sociedade e aqueles das comunidades que estuda" (ibidem, p. 694). Sem ignorar as diferenças, o estudo do trabalho do ator entre Oriente e Ocidente pode procurar um território comum de prática cênica que una diferentes tradições ao redor das mesmas questôes, ainda que cada uma as tenha elaborado e resolvido de maneira profundamente diversa. O que nos interessa é justamente esta diversidade para além do exotismo, pois através dela podemos abrir nosso horizonte e repensar conceitos e definições que nos pareciam inquestionáveis.

\section{A Poética e o Natyasastra}

Na tentativa de traçar uma estratégia que nos permita transitar entre Oriente e Ocidente, 
analisaremos alguns aspectos que dizem respeito ao trabalho do ator em dois textos fundamentais para estas tradições: a Poética de Aristóteles, texto que inaugura a reflexão ocidental sobre o teatro, e o Natyasastra, cuja autoria é atribuída ao mítico Bharata Muni, ${ }^{1}$ uma referência fundamental para a cultura cênica indiana e, portanto, também para uma boa parte da Ásia, que reconhece na Índia uma fonte ancestral de sua cultura teatral. ${ }^{2}$

O Natyasastra é um tratado sobre o natya, palavra que é normalmente traduzida como "arte do teatro", mas seria mais corretamente a "arte do teatro que dança”, pois "não só deriva da raiz sânscrita nrit, que possui o inequívoco significado de dança, como designa uma realidade muito mais próxima a um teatro dançado que falado" (Savarese, 1992, p. 173). Seu período de composição é extremamente controverso: as datas variam entre os séculos VI a.C. e II d.C., de acordo com os diferentes historiadores. Sua importância não está no fato de ser o primeiro livro sobre o natya, mas no fato de ser o mais completo. Podemos dizer a seu respeito que "o que aqui se encontra talvez possa ser encontrado em outro lugar, mas o que não está aqui não pode ser encontrado em lugar nenhum" (Rangacharya, 1996, p. 207).

Até a segunda metade do século XIX o Natyasastra não havia sido publicado, apesar de ter sido interpretado por diversos comentadores no curso dos séculos. Foram os orientalistas ocidentais os primeiros a tentar estabelecer unidade e coerência - ainda não alcançada ${ }^{3}$ - nos diversos manuscritos dispersos. Esta difusão fragmentária do texto nos demonstra que mais que um texto literário ele é um conjunto de preceitos práticos. $\mathrm{O}$ teatro que ele descreve não exis- te atualmente, mas as múltiplas tradições que constituem a arte cênica clássica indiana cresceram sob a sua influência.

O Natyasastra é um livro escrito por e para os praticantes do natya, que descreve minuciosamente todos os mínimos detalhes desta arte. A Poética foi escrita por um filósofo, do ponto de vista do espectador/leitor e não trata especificamente do teatro grego enquanto fenômeno espetacular, mas se concentra na análise da tragédia e da epopéia enquanto obras poéticas. Na Poética a poesia é definida como a imitação de uma ação humana. O núcleo fundamental da tragédia é a trama dos fatos, contida no texto, mas a especificidade da tragédia (em relação à epopéia) é que esta imita "não por narrativa, mas mediante atores" (Aristóteles, 1987, p. 205). Entretanto o trabalho específico do ator é contemplado apenas indiretamente, enquanto um aspecto da elocução (enunciado do pensamento por meio de palavras) "que consiste em saber o que é uma ordem ou uma súplica, uma explicação, uma ameaça, uma pergunta, uma resposta e outras que tais" (id., ibid., p. 218), ou por via negativa, como uma reprovação aos maus atores pela sua gesticulação exagerada e vulgar (id., ibid., p. 228). Aristóteles, embora considere que a música e o espetáculo cênico "acrescem [à tragédia] a intensidade dos prazeres que lhe são próprios" (id., ibidem), reivindica a autonomia do texto em relação à cena:

Quanto ao espetáculo cênico, decerto que é o [elemento] mais emocionante, mas também é o menos artístico e o menos próprio da poesia. Na verdade, mesmo sem representação e sem atores, pode a tragédia manifestar seus efeitos (id., ibid., p. 207).

1 Não existe nenhuma evidência de que Bharata Muni seja uma personagem histórico. Muni quer dizer "sábio" e Bharata seria na realidade um acróstico de bhava (sentimento), raga (melodia) e tala (ritmo).

2 Zeami, o fundador do Nô, por exemplo, afirma que sua arte é originária "da Pátria do Budha" (Zeami, 1987, p. 73).

3 “(...) o texto final é contraditório, repetitivo e incongruente; existem também lacunas, mas, o que é pior, existem palavras e passagens que são quase impossíveis de entender” (Rangacharya, 1996, p. xviii). 
Desse modo, Aristóteles reconhece a importância da cena quando coloca a música e o espetáculo como elementos constitutivos da tragédia, mas estabelece uma hierarquia onde estes elementos devem estar a serviço da trama dos fatos descrita no texto. No século XVII, os comentadores da Poética, a partir de uma interpretação simplista da argumentação aristotélica, estabeleceram a total supremacia do texto sobre todos os outros elementos que fazem parte do fenômeno teatral. Essa visão "logocêntrica", que caracterizou a tradição teatral do Ocidente até o final do século XIX e ainda hoje exerce uma grande influência no pensamento sobre o teatro, determinou para a cena, que se dirige aos sentidos, um papel periférico em relação ao texto que apesar de precisar dos sentidos para chegar ao espectador, se dirige ao espírito.

O Natyasastra também considera o natya como uma forma de poesia, mas ele é uma "poesia visual" (drsya kavya), ou seja, uma composição poética que não pode ser apreciada através da leitura, mas somente através da encenação. A trama é apenas um dos elementos que, junto com outros estímulos visuais e sonoros, envolve o espectador em uma experiência estética. $\mathrm{O}$ trabalho do nata - assim é chamado o ator/dançarino no Natyasastra - não está ligado unicamente à ação veiculada pelo texto, mas se relaciona com todos os elementos que fazem parte da cena e principalmente com a música, cujo aspecto rítmico é para ele de importância fundamental.

Assim, algumas das diferentes funções atribuídas na Poética ao poeta, que deve usar uma "linguagem ornamentada (...) que tem ritmo e harmonia" (id., ibid., p. 205), ao ator, que deve imitar as ações usando como meios os gestos e a elocução, e aos dançarinos, que "por gestos ritmados imitam caráteres, afetos e açôes", (id., ibid., p. 201) se sobrepõem no trabalho do ator/dançarino da tradição clássica indiana que "fala" através dos hastas - gestos simbólicos e movimentos ritmados que não se limitam a imitar paixões e ações, mas são como ideogramas corporais que desenvolvem uma "linguagem ornamentada” análoga àquela do poeta.

No teatro descrito no Natyasastra, o nata também usava a voz, mas na maior parte dos estilos atuais de teatro-dança clássico indiano a linguagem verbal é confiada aos cantores. ${ }^{4}$ Concentrando-se unicamente nos movimentos físicos, o ator indiano pode desenvolver uma linguagem corporal extremamente sofisticada, que permanece em estreito contato com o texto, que não só é "traduzido" em gestos, palavra por palavra, mas é também comentado e enriquecido com imagens poéticas. "Sua língua permanece em silêncio, mas todo seu corpo fala através de signos e de movimentos" (Tagore, citado em Gosh, 1975, p. 9).

Para estruturar seus movimentos com a densidade necessária para desenvolver esta linguagem simbólica e poética, o ator/dançarino indiano deve ser capaz de segmentar seu corpo em unidades mínimas. Estes segmentos trabalham em harmonia, mas com independência, de modo que, ao mesmo tempo, diversas partes do corpo executem tarefas diferentes, usando, segundo a expressão cunhada por Vescovi, a técnica do "corpo-orquestra" (Vescovi, 1993, p. 27-46) Esta segmentação é contemplada no Natyasastra, que descreve os movimentos particulares de cada pequena parte do corpo (tronco, membros, mãos, pés, cabeça, olhos etc.) e suas funções, assim como no Abhinaya Darpana, um pequeno tratado sobre o natya, escrito provavelmente no século III d.C., que pode ser considerado uma espécie de "comentário" do Natyasastra, onde o mesmo conceito é definido com esta formula:

4 A excessão a essa regra é o Koothu (Chakiar Koothu, Nangiar Koothu e Koodiyattam) a única forma de teatro sânscrito que ainda hoje é representada na Índia, no estado do Kerala, onde os atores/dançarinos utilizam uma técnica muito refinada que envolve olhos, gestos (hastas) e voz. 
O canto deve ser sustentado pela garganta; seu significado expresso pelas mãos; o sentimento (bhava) deve ser expresso pelo olhar; o ritmo (tala) é marcado pelos pés. Para onde se move a mão, o olhar segue; aonde vai o olhar, segue a mente; aonde a mente vai, o sentimento segue; aonde vai o sentimento, lá está o sabor (rasa) (Coomaraswamy, 2003, p. 17).

Deste modo, usando seu "corpo-orquestra", o nata deve proporcionar ao espectador uma experiência estética que é definida com a palavra "rasa", que significa literalmente "sabor":

Exatamente como se produz um sabor agradável através do molho produzido quando diferentes temperos, ervas e outros artigos são misturados, o rasa é produzido quando vários bhavas são combinados (Ghosh, 1995, p. 81),

O rasa é a síntese ou mistura de diversos elementos, mas esta síntese não significa indistinção. O Natyasastra descreve com grande sutileza psicológica os diferentes elementos que devem se combinar para produzir o rasa e estabelece uma distinção entre este e o bhava. Esta distinção é complexa, pois estes conceitos designam sentimentos ou estados de ânimo que, apesar de intimamente ligados e até mesmo interdependentes, são profundamente diversos. Proporcionar a experiência de um determinado rasa ao espectador é o fim último da arte dramática indiana e para realizar este objetivo o ator deve expressar o bhava correspondente. Deste modo, podemos dizer que rasa e bhava se referem a uma mesma experiência vista do ponto de vista do espectador e do ator, sendo o rasa correspondente ao sabor de um determinado alimento ou tempero e o bhava o próprio alimento que provoca este sabor.

Existem vários tipos de bhava que combinados provocam o rasa. Inicialmente existe o vibhava, o sentimento determinante, que surge a partir da compreensão da situação exposta pelo texto e pela música; deste vibhava surgirá um sthayi bhava, ou sentimento dominante, que condicionará todo o comportamento da personagem durante a ação. Este comportamento pode se desenvolver em três tipos de manifestações: anubhavas, ou voluntárias (executadas no sentido de expressar o sthayi bhava); vyabhicari bhavas, ou transitórias (ligadas a sentimentos momentâneos que estão em relação com o sthayi bhava, mas apenas dentro do contexto da ação em um determinado momento) e finalmente sattvika bhavas, ou involuntárias (manifestaçōes involuntárias do sthayi bhava, ligadas à emoção do momento).

Essas condições, emoções e ações, porém não são individuais ou casuais, mas obedecem a regras precisas e estão umas em correspondência com as outras, de modo que um determinado vibhava despertará um sthayi bhava preciso que se manifestará em determinados anubhavas, vyabhicari bhavas e sattvika bhavas, provocando um determinado rasa. Segundo o Natyasastra existem oito sthayi bhavas e oito rasas correspondentes:

$\begin{array}{lll}\text { sthayi bhava } & \text { rasa } & \text { tradução } \\ \text { rati } & \text { srngara } & \text { amor, desejo } \\ \text { hasa } & \text { hasya } & \text { ironia, escárnio } \\ \text { soka } & \text { karuna } & \text { tristeza, compaixão } \\ \text { krodha } & \text { raudra } & \text { ira } \\ \text { utsaha } & \text { vira } & \text { heroísmo, vigor } \\ \text { bhaya } & \text { bhayanaka } & \text { medo } \\ \text { jugpsa } & \text { bibhatsa } & \text { asco } \\ \text { vismaya } & \text { adbhuta } & \text { surpresa, deslumbramento }\end{array}$

A palavra sânscrita para definir o trabalho do nata é "abhinaya", formada pelo prefixo "abhi" (em direção a) e pela raiz " $i$ " (carregar). Através do abhinaya, o nata expressa os bhavas que levam o espectador à experiência do rasa. Para realizar esta operação o abhinaya é composto de quatro partes: angika (movimentos corporais), vacika (uso da voz), aharya (figurino e maquiagem) e sattvika (estados psicológicos). Estas partes do abhinaya são consideradas como atributos de Shiva Nataraja, o deus Shiva 
na sua veste de rei (raja) dos natas, e são expressas nesta prece que inicia o Abhinaya Darpana:

\author{
angikam bhuvanam \\ [teu corpo é o universo] \\ yasya vacikam sarva vangmayam \\ [tua voz fala todas as línguas] \\ aharyam chandra taradi \\ [tuas vestes são a lua e as estrelas] \\ tam numah sattvikam Shivam
}

[diante de ti me curvo, ó divino Shiva]

(Coomaraswamy, 2003, p. 13).

Dos diferentes abhinayas, o sattvika abhinaya é o mais importante e o mais dificíl de definir. Sattva significa literalmente "originário da mente". Segundo o Natyasastra ele é "algo não-manifesto, mas que é o fundamento do bhava e do rasa" (Gosh, 1995, p. 373). O sattvika abhinaya é usado para expressar os sattvika bhavas, que são reaçôes involuntárias e por isso não podem ser alcançadas diretamente, mas surgem quando a mente está especialmente concentrada. Naturalmente os sattvika bhavas não podem expressar-se senão através do corpo (através de alterações sutis na fala, na respiração, nos gestos e expressões, ou em ações mais evidentes como o choro) mas não estão relacionados com o angika abhinaya porque não podem ser trabalhados tecnicamente, mas devem vir de dentro do próprio ser e manifestar-se espontaneamente.

\section{Questões iguais, respostas diferentes}

Como pode a tristeza ser representada por alguém que não está triste? Como pode a felicidade ser representada por alguém que não está alegre? (id., ibid., p. 113).

Konstantin Stanislavski, que na primeira metade do século XX criou novos fundamentos para o trabalho do ator ocidental, se colocou mais ou menos a mesma questão sobre a representação cênica dos sentimentos. Ele também procurava "algo não-manifesto" e sabia que só era possível chegar a este "algo" por uma via indireta. Partindo do trabalho sobre si mesmo o ator stanislavskiano, lançando mão de uma série de técnicas psicofísicas (o "se mágico", as "circunstâncias dadas" etc.), tenta compreender as motivaçôes das ações da personagem e construir seu comportamento físico dentro de um processo de identificação.

Desse modo, o aprendizado do ator, segundo Stanislavski, principia com as técnicas psicológicas, mas não será completo sem o domínio das técnicas corporais que permitem ao ator exprimir a vida interior da personagem.

Não se pode comunicar o delicado processo interior da vida espiritual do homem com um corpo sem treinamento, do mesmo modo que não se pode tocar a nona sinfonia de Beethoven com um instrumento desafinado (Stanislavski, 1968, p. 379).

No início do aprendizado do ator oriental não existe aparentemente nenhuma preocupação com os aspectos internos do processo criativo. Esses anos são dedicados a tornar o corpo forte e flexível, pronto para a perfeição das formas e o domínio das convenções. Nesse período não é importante que o estudante compreenda as motivações de um determinado gesto ou atitude; é suficiente que ele procure reproduzi-lo o mais fielmente possível. Quando chegar o momento de encarnar uma personagem, seu comportamento físico não será deixado ao acaso ou à sua invenção: será determinado por uma estrutura já fixada pela tradição, tão precisa como a música ou o texto. Mas para evocar um determinado rasa não é suficiente repetir minuciosamente determinados movimentos e expressões. O ator deverá levar em conta as nuances de cada história e de cada cena e usar esta partitura de gestos e açôes codificadas - que apesar da grande estilização estão enraizadas na vida quotidiana - como um ponto de partida. No seu trabalho criativo, ele se concentrará na maneira de executar a partitura, no jogo rítmico, nos pequenos detalhes de execução. 
Jerzy Grotowski, durante sua conferência Oriente/Ocidente, nos fala sobre a diferença do conceito de ação para um ator ocidental e para um ator oriental, tomando como exemplo a ação de caminhar. Para o ator oriental importante é a maneira de caminhar, o seu modus operandi:

Para um ator do teatro clássico chinês ou do Nô japonês existe algo que é o modus operandi de caminhar. Pode-se dizer (brincando com a terminologia de Heidegger), que para ele não existe só a ação de "walking", existe "walkness" (...) é como renunciar à nossa própria subjetividade e ocupar-nos das leis mesmas da ação. O que é caminhar? Aqui estamos diante da desconexão dos pequenos movimentos que compõem a ação. (...) O que é, então, caminhar sem objetivo, sem ser capturado pelo objetivo da nossa subjetividade? (Grotowski, 1993, p. 64).

Para o ator ocidental, essa relação sujeito/ objeto é fundamental para seu trabalho e a ação é um instrumento para concretizar essa relação. A ação é importante enquanto é o meio para atingir um objetivo, ela só existe se possui um objetivo. Desse modo, olhando o trabalho do ator oriental com olhos ocidentais, não podemos dizer que este executa açôes. "O estudo de uma ação com a separação dos elementos de movimento conduz aos signos das ações, em lugar das ações" (id., ibidem).

Segundo Grotowski, porém, Stanislavski no final da sua vida também vai se ocupar das leis que regem e organizam as açôes físicas, pois chegou à conclusão de que os sentimentos não dependem da nossa vontade:

Não me falem em sentimentos, não podemos fixar os sentimentos. Podemos fixar e recordar somente as ações físicas (Toporkov, 1991, p. 111).

É impossível representar um sentimento. O sentimento é pela sua própria natureza, tão sutil que se esconde ao toque do pensamento. Podemos fazer apenas uma coisa: sondar a natureza de um sentimento, examinar o que vive no pensamento e como se desenvolve um movimento físico sobre a influência desta ou daquela reação (Stanislavski, 1980, p. 155).

Em relação ao seu trabalho precedente existe uma mudança de orientação. Até então Stanislavski acreditava que usando técnicas psicológicas como a "memória emotiva" fosse possível trabalhar voluntariamente com os sentimentos. Nesta nova fase, ele vai pedir ao ator para se concentrar apenas nas ações físicas que executa: "Teu objetivo é pedir silêncio, mas todas as tuas reaçôes, a tua maneira de escutar e de ouvir, a tua maneira de reconhecer a situação, tudo vai ser feito através de ações físicas, ou seja, pela tua maneira de caminhar" (Grotowski, 1993, p. 64). A linha de açôes físicas permite ao ator penetrar no universo interior $\mathrm{da}$ personagem:

Através de uma ação física, como levantar-se de uma cadeira, você pode me conduzir imediatamente ao centro da tua vida interior. Eu saberei imediatamente quem e o que você é, o que te faz feliz ou infeliz (Stanislavski, 1980, p. 155).

Todavia, esta preocupação com as ações físicas ainda é muito distante da "ação sem objetivo" do ator oriental; e não poderia ser diversamente, pois como vimos, de acordo com a tradição ocidental o objetivo do teatro é contar uma história e para a tradição oriental o importante é a "degustação" de um sentimento estético.

Tradição deriva do latim tradere, cujo significado é o de transmitir. No próprio ato da transmissão, algo permanece, mas necessariamente algo também se modifica. $\mathrm{O}$ ator, oriental ou ocidental, como qualquer artista, se banha no rio da tradição, que é este processo vivo de transmissão, que implica em permanência e transformação. Existe porém uma especificidade 
no seu trabalho: o caráter efêmero do evento espetacular, que faz com que sua obra permaneça apenas na memória de seus espectadores ou na transmissão direta de suas técnicas aos atores mais jovens.

A cultura do ator é acima de tudo cultura de acumulação. O novo ator se forma imitando o velho, para depois se oferecer à imitação de seus sucessores, e em cada passagem, junto com as variantes da arte pessoal, se acumulam heranças nos corpos dos intérpretes. É o elemento cultural da condição do ator enquanto espécie, em perene contraste com a lógica do efêmero que lhe é inerente (Meldolesi, 1989, p. 209).

Nesta relação entre as "heranças que se acumulam no corpo" e as "variantes da arte pessoal" o ator constrói sua arte, mas ao contrário dos outros artistas, "o ator não comunica ao espectador um resultado, mas a sensação física correspondente a um resultado expressivo pré-ordenado" (ibidem, p. 213). Em outras palavras, a arte do ator é a execução de sua partitura diante do espectador. A relação entre o respeito a uma estrutura formal e a expressão de sua própria subjetividade é o elemento constitutivo do trabalho do ator, pois a sua arte não se concretiza em uma obra acabada, mas em uma performance.

Nas tradiçõos cênicas européias e asiáticas, esses processos de transmissão têm histórias fundamentalmente diversas. No seu aprendiza- do, o ator da tradição cênica oriental tem à sua disposição um grande repertório de ações que é fruto do trabalho de várias gerações. $\mathrm{O}$ "grande ator" oriental é capaz de executar com grande precisão e maestria este repertório, e talvez até introduzir alguma pequena inovação que será por sua vez incorporada à tradição. Essa tradição, que repousa em muitos séculos de transmissão mais ou menos ininterrupta, proporciona uma base material para sua arte, ainda que aparentemente restringindo a criatividade individual e aprisionando-o dentro de uma forma preestabelecida. O ator ocidental contemporâneo, por outro lado, é livre para reinventar a cada vez uma nova forma, mas é prisioneiro do arbítrio e da falta de regras precisas que orientem sua criatividade, como se a cada vez ele devesse começar do zero, "inventando" a sua própria tradição.

Entretanto, é preciso estar atento para não idealizar esses processos de transmissão. Assim como o ator ocidental não pode realmente começar do zero, pois é impossível não se confrontar com a tradição, mesmo que seja dentro de um processo de ruptura, o ator oriental não vive em um mundo à parte, livre da influência das mudanças históricas. As questōes que cada ator deve enfrentar, ainda que em contextos completamente diferentes, são mais ou menos as mesmas. As respostas não serão iguais, mas estas devem necessariamente ser diferentes. Em qualquer latitude, cada um deve se confrontar com a sua própria tradição e encontrar as suas próprias respostas. 


\section{Referências bibliográficas}

ARISTÓTELES. Poética. Trad. de Eudoro de Souza. Col. Os Pensadores. São Paulo: Nova Cultural, 1987.

COOMARASWAMY, A. The mirror of gesture - being the Abhinaya Darpana of Nandiveskara. New Delhi: Munshiram Manoharlal, 2003.

GOSH, M. Nandiveskara's Abhinaya Darpana. Calcutta: Manisha Granthalaya, 1975. . The Natyasastra. Calcutta: Manisha Granthalaya, 1995.

GROTOWSKI, J. Oriente/Ocidente. In: Máscara (Año 3 n. 11-12). México D.F.: Escenología, 1993.

MELDOLESI, C. "L'attore, le sue fonti e i suoi orizzonti". In: Teatro e Storia (Anno IV, n. 2). Bologna: Il Mulino, 1989.

RANGACHARYA, A. The Natyasastra. New Delhi: Munshiram Manoharlal, 1996.

SAVARESE, N. Teatro e spettacolo fra Oriente e Occidente. Roma: Laterza, 1992.

SEEGER, A. "Music and dance". In: Companion encyclopedia of anthropology. London: Routledge, 1997.

STANISLAVSKI, K. S. Il lavoro dell'attore. Roma: Laterza, 1968.

. L'attore creativo. Firenze: Casa Usher, 1980.

TOPORKOV, V. O. Stanislavski alle prove. Milano: Ubulibri, 1991.

VESCOVI, R. L'attore "lirico" - appunti sull'arte dell'attore fra Oriente e Occidente. In: Necessità e libertà. Lecco: Il Comballo, 1993.

ZEAMI, M. Il segreto del teatro No. Milano: Adelphi, 1987. 